\title{
A conditional-lethal mutant of Bacillus subtilis 168 with a thermosensitive glycerol-3-phosphate cytidylyltransferase, an enzyme specific for the synthesis of the major wall teichoic acid
}

\author{
Harold M. Pooley, François-Xavier Abellan and Dimitri Karamata* \\ Institut de Génétique et Biologie Microbiennes, Rue César-Roux 19, 1005 Lausanne, Switzerland
}

(Received 11 October 1990; revised 19 November 1990; accepted 11 December 1990)

\begin{abstract}
A biochemical analysis was undertaken of thermosensitive mutants of Bacillus subtilis 168 harbouring mutations in several tag genes, involved in the synthesis of the major wall teichoic acid, poly(glycerol phosphate), poly(groP). Incorporation of a pulse of $\left[2-{ }^{3} \mathrm{H}\right]$ glycerol into whole cells, following shift to the restrictive growth temperature, was used to assess synthesis of this polymer and to seek evidence of accumulation of a specific precursor. The rate of incorporation into poly (groP) was strongly decreased in all mutants; glycerol uptake was diminished by $80 \%$ or more for a strain harbouring mutation $\operatorname{tag} B 1$ (formerly tag-1) and one bearing $\operatorname{tag} D 11$ (formerly tag-11). The pool of CDP-glycerol (CDP-gro), a specific precursor of poly(groP), was increased, relative to the wild-type, for all mutations except tagD11, where the pool of CDP-gro was reduced. Cytoplasmic extracts, assayed at the permissive temperature for glycerol-3-phosphate cytidylyltransferase (gro-PCT), the enzyme synthesizing CDPgro, revealed wild-type activities for all mutations except $\operatorname{tag} D 11$. Gro-PCT activity in the latter strain was 100fold lower and, unlike that in all other mutant strains, highly thermolabile. This thermosensitivity suggests that tag $D$ encodes gro-PCT. The identification, in a gene encoding a poly(groP)-specific enzyme, of a mutation conferring a thermosensitive growth phenotype renders explicit the conclusion that synthesis of this teichoic acid is essential for the growth of $B$. subtilis.
\end{abstract}

\section{Introduction}

Initial genetic and biochemical characterization of a collection of conditional-lethal thermosensitive mutants of Bacillus subtilis revealed major defects in their cell shape and cell wall teichoic acid content (Briehl et al., 1989). The relevant mutations were mapped at around $310^{\circ}$ on the chromosome in at least two genes involved in synthesis of poly(glycerolphosphate), poly(groP) (Briehl et al., 1989; Honeyman \& Stewart, 1989; Mauël et al., 1989). The conclusion that several genes specifically concerned with the synthesis of poly(groP) are located in this region was inferred from the analysis of $B$. subtilis 168/W23 strains hybrid for teichoic acids (Karamata et al., 1987). Previously, a mutation, $\operatorname{tag} B I$ (formerly tag- $I$ ), that mapped in the same region and showed a similar phenotype (Boylan et al., 1972), was considered to affect the synthesis of poly(groP), although no specific enzyme

Abbreviations: BSA, bovine serum albumin; $\alpha$-groP, $\alpha$-glycerol 3phosphate; gro-PCT, glycerol-3-phosphate cytidylyltransferase; poly(groP), poly(glycerol phosphate); ND, nephelometric density; PG, peptidoglycan.

$0001-6566$ (C) 1991 SGM deficiency was identified (see below). Subsequent studies (Rogers et al., 1974) with $\operatorname{tagBI}$ challenged the view that teichoic acid synthesis was the mutational target and proposed that the apparent decrease in wall teichoic acid was due to a major derepression of peptidoglycan synthesis. Although the same authors later showed that a significant $50-75 \%$ inhibition in the absolute rate of teichoic acid synthesis did indeed follow transfer of this mutant to the restrictive temperature (Rogers \& Taylor, 1978), no conclusion was made concerning the nature of the function encoded by $\operatorname{tag} B$. Furthermore, a mutation in the $\operatorname{rod} B$ locus, located at $247^{\circ}$, associated with a cell morphology similar to that of $\operatorname{tag} B 1$ and other linked mutations (Briehl et al., 1989; Karamata et al., 1972), was shown not to affect teichoic acid synthesis (Rogers et al., 1971). Thus, the major gap in the evidence linking tag genes to the synthesis of poly(groP) (Karamata et al., 1987; Briehl et al., 1989; Mauël et al., 1989) is the failure, so far, to identify, among tag gene products, a single teichoic acid specific enzyme. Indeed, the activities of three teichoic acid specific enzymes, the glycerol-3phosphate cytidylyltransferase (gro-PCT), CDP-glycerol poly(glycerol phosphate) transferase and UDP-glucose 
poly(glycerol phosphate)- $\alpha$-glucosyltransferase were all apparently normal in a strain bearing $\operatorname{tag} B 1$ (Boylan $e t$ al., 1972). Equally, in several mutants of Staphylococcus aureus lacking the ribitol teichoic acid of the cell wall (Shaw et al., 1970), and exhibiting a sevenfold accumulation of a specific soluble precursor, CDP-ribitol, no specific enzymic deficiencies were identified.

We report here a preliminary biochemical analysis of mutants bearing mutations in different tag genes and the identification of the gene which encodes gro-PCT, an enzyme specifically concerned with the synthesis of poly(groP).

\section{Methods}

Bacteria. The strains of B. subtilis 168 used are listed in Table 1 . Apart from tagB1 (formerly tag-l) (Boylan \& Mendelson, 1969) and tagFl (formerly rodCl) (Karamata et al., 1972), all tag mutations were identified among a collection of mutants with a conditional lethal thermosensitive phenotype (Briehl et al., 1989).

Media. TS plates and liquid medium SAT, containing glucose and supplemented where necessary with $100 \mu \mathrm{g}$ adenine $\mathrm{ml}^{-1}$, have been described (Karamata \& Gross, 1970; Briehl et al., 1989). Growth was followed by nephelometric density (ND). A ND of 1 corresponds to $1.34 \mu \mathrm{g}$ bacterial dry weight $\mathrm{ml}^{-1}$.

Chemicals. $\left[2-{ }^{3} \mathrm{H}\right]$ Glycerol and $\mathrm{L}-\left[\alpha^{-14} \mathrm{C}\right]$ glycerol phosphate were obtained from Amersham, cytidine 5'-mono (CMP), -di (CDP) and -tri (CTP) phosphates from Fluka (Switzerland), cytidine 5'-diphosphogly- cerol and L- $\alpha$-glycerol 3-phosphate ( $\alpha$-groP) from Sigma, activated charcoal from Merck, and Superose 12 from Pharmacia.

Extraction of soluble precursors, including CDP-glycerol, from cultures of thermosensitive mutants pulse-labelled with $\left[2{ }^{3} \mathrm{H}\right]$ glycerol following shift to a restrictive temperature. $\left[2{ }^{3} \mathrm{H}\right]$ Glycerol was employed to specifically label glycerol-containing precursors and macromolecules since metabolic conversion of glycerol to dihydroxyacetone phosphate leads to loss of the label from the C-2 position to the water pool (Daniels, 1969), so that ensuing intermediary metabolites derived from glycerol are unlabelled.

Exponential-phase seed cultures, grown for $16 \mathrm{~h}$ at $22^{\circ} \mathrm{C}$ in SAT supplemented with $200 \mu \mathrm{M}$-glycerol, were diluted into the same medium to a ND of 10 and incubated with aeration at $30^{\circ} \mathrm{C}$, the permissive temperature. At a ND of 100 , to diminish the growthinhibitory effects of a sudden shift, the temperature was progressively raised to $47^{\circ} \mathrm{C}$ over a $12-14$ min interval. Immediately upon reaching $47^{\circ} \mathrm{C}$, a 4-5-fold dilution was made (to a ND of 40 ) into the same medium supplemented with $0.4 \mu \mathrm{Ci} \mathrm{m}]^{-1}$ of $\left[2-{ }^{3} \mathrm{H}\right] \mathrm{glycerol}$ [specific activity $2 \mathrm{Ci} \mathrm{mol}^{-1}, 74 \mathrm{GBq} \mathrm{mol}^{-1}$ ). After a $5 \mathrm{~min}$ pulse, duplicate $5 \mathrm{ml}$ samples were filtered, washed with water and resuspended in $1 \mathrm{ml}$ water. The suspension was placed in a boiling water bath for $40 \mathrm{~min}$ to extract the pool of soluble glycerol-labelled precursors, which was separated from the insoluble cell fraction by filtration. After a $20 \mathrm{~min}$ treatment of the filter with $1 \mathrm{ml} 0 \cdot 1 \mathrm{M}-\mathrm{NaOH}$ at $100{ }^{\circ} \mathrm{C}$, the total radioactivity incorporated was determined by scintillation counting in $10 \mathrm{ml}$ of Optifluor (Packard).

The concentration of nucleotide-containing precursors in the extract was estimated according to Strominger (1962). Nucleotide-containing precursors were then separated by selective adsorption onto activated charcoal added in amounts equivalent to $20 \mathrm{mg}$ per $\mu \mathrm{mol}$ of nucleotide. After gentle shaking for $20 \mathrm{~min}$, at room temperature, the charcoal was pelleted and washed twice with $1 \mathrm{ml} 100 \mathrm{~mm}$-ammonium acetate. Adsorbed nucleotides were eluted with $50 \%(\mathrm{v} / \mathrm{v})$ ethanol in water/

Table 1. Bacillus subtilis strains

\begin{tabular}{|c|c|c|}
\hline Strain & Genotype & Reference or construction \\
\hline L5025 & purA16 leuA8 ilval lys-3I & Brandt \& Karamata (1987) \\
\hline L5087 & his Al $\operatorname{argC} 4$ metC3 & Briehl et al. (1989) \\
\hline L6601 & hisAl argC 4 metC $3 \operatorname{tag} D 11^{*} \dagger \ddagger$ & Briehl et al. (1989) \\
\hline L6456 & purAl6 hisAl argC4 metC3 tagFl+† & Briehl et al. (1989) \\
\hline L6476 & his Al argC4 metC3 tagBl & Briehl et al. (1989) \\
\hline L6477 & hisAl argC4 metC3 tagFI† & Briehl et al. (1989) \\
\hline L6604 & his $\mathrm{Al}$ argC 4 metC 3 tagFl4† & Briehl et al. (1989) \\
\hline L6605 & hisAl argC4 metC 3 tagFls & Briehl et al. (1989) \\
\hline L6651 & leuA8 ilvAI lys-31 tagD11 $\dagger$ & Congression of L6601 $\rightarrow \mathrm{L} 5025$ \\
\hline L6653 & leuA8 ilvAl lys-3l tagBI & Congression of L6476 $\rightarrow \mathrm{L} 5025$ \\
\hline L6654 & leuA8 ilval lys-3l tagFI† & Congression of $\mathrm{L} 6477 \rightarrow \mathrm{L} 5025$ \\
\hline L2100 & leuA8 ilval lys-31 & Brandt \& Karamata (1987) \\
\hline L2129 & leuA8 ilval lys-31 lss $A 29$ & Brandt \& Karamata (1987) \\
\hline L2123 & leuA8 ilvA1 lys-31 lssB23 & Brandt \& Karamata (1987) \\
\hline
\end{tabular}

* Formerly tag- 11 (Briehl et al., 1989). Mutations tag-11 and tag-12 have probably arisen from the same clone, not being separated in transformation crosses (Briehl et al., 1989). $\left[2-{ }^{3} \mathrm{H}\right]$ Glycerol incorporation into soluble and macromolecular fractions associated with $\mathrm{tag}-12$ (not shown) were indistinguishable from those shown here for tagD11.

$\dagger$ Distinctive colony morphology on TS plates at $30^{\circ} \mathrm{C}$; smaller, smoother and more raised colonies than those of the wild-type.

$\ddagger$ The assignment of $\operatorname{tag}$ mutations to genes labelled $\operatorname{tag} A$ to $F$ comes from Mauël $e t$ al. (1991). tagFl was formerly rodCl (Karamata et al., 1972), tag-3 (Pooley et al., 1987), or $\operatorname{tag} B 3$ (Mauël et al., 1989). tagBI was formerly tag-I (Boylan et al., 1972), $\operatorname{rodA}$ (Rogers et al., 1974), or tagAl (Mauël et al., 1989). 
$0.05 \mathrm{M}-\mathrm{NH}_{4} \mathrm{OH}(1: 1, \mathrm{v} / \mathrm{v})$ by one of the following methods: (i) two $40 \mathrm{~min}$ treatments at room temperature with gentle shaking (Strominger, 1962), or (ii) a $60 \mathrm{~min}$ incubation at $70^{\circ} \mathrm{C}$ (Glaser, 1965). The recovery, of approximately $80 \%$, was slightly better with the second method. Eluted radioactivity was determined in the same way as that on the filters.

Paper chromatography. Presence of CDP- $\left[2-{ }^{3} \mathrm{H}\right]$ glycerol in the hotwater extract of cells pulse labelled with $\left[2-{ }^{3} \mathrm{H}\right] \mathrm{glycerol}$ was determined according to Paladini \& Leloir (1952) by descending chromatography on Whatman no. 3MM paper using solvents (A) ethanol/1 Mammonium acetate, $\mathrm{pH} 7.8(7.5: 3, \mathrm{v} / \mathrm{v})$ and (B) ethanol/1 M-ammonium acetate, $\mathrm{pH} 3.8(7.5: 3, \mathrm{v} / \mathrm{v})$. Presence of sugar phosphates was established by the method of Bandursky \& Axelrod (1952) and their position compared with those of authentic standards. Adequate separation of CDP-glycerol, UDP- $N$-acetylglucosamine, $\alpha$-groP, glycerol, CMP, CDP and CTP standards, was obtained and $R_{F}$ values agreed with previous results (Glaser, 1965 ; Glaser \& Loewy, 1979). Scintillation counting revealed that $90 \%$ of the radioactivity in the nucleotide-containing fraction (see above, and Results) of the hotwater extract co-chromatographed with a CDP-glycerol standard.

Transformations. These were performed as previously described (Karamata \& Gross, 1970).

Preparation of a crude cytosol fraction for assay of gro-PCT. Following several control experiments, the method adopted for crude cytosol preparation was that described by Glaser \& Loewy (1979) modified as follows: the washing step, involving resuspension in buffer and resedimentation of the harvested cell pellet, was replaced by a simple rinse, with medium, prior to resuspension in buffer for cell breakage. This modification was accompanied by a $70 \%$ increase in final specific activity of the gro-PCT. A seed culture grown at $22^{\circ} \mathrm{C}$ for $16 \mathrm{~h}$ in SAT supplemented with $200 \mu \mathrm{M}$-glycerol was diluted to ND 10 in the same medium and incubated at $30^{\circ} \mathrm{C}$. At ND 100 , the culture $(200 \mathrm{ml})$ was harvested by centrifugation at 8000 r.p.m. (Sorvall rotor GSA). The pellet, after being rinsed (Pooley et al. , 1987) with the same medium, was resuspended in $3.5 \mathrm{ml}$ TEM buffer $(50 \mathrm{~mm}-\mathrm{Tris} / \mathrm{HCl} \mathrm{pH} 7.5$, $10 \mathrm{mM}-\mathrm{MgCl}_{2}, 1 \mathrm{mM}$-EDTA). Cells were broken by three passages through a French press. Centrifugation at 18000 r.p.m. for $15 \mathrm{~min}$ yielded a pellet of walls, membranes and unbroken cells. The supernatant containing the soluble fraction of the cell was either assayed for gro-PCT immediately, or small aliquots were frozen rapidly and stored at $-70^{\circ} \mathrm{C}$. No significant loss of gro-PCT activity in frozen extracts (thawed once only) was noticed during a three month period. The protein content of the cytosol was assayed by the method of Bradford (1976).

Assay of gro-PCT in cytosolic extracts. The reaction

L- $\alpha$-Glycerol 3-phosphate $+\mathrm{CTP} \leftrightarrow \mathrm{CDP}$-glycerol + pyrophosphate

was measured by a radioassay in the direction of CDP-glycerol formation as described by Glaser \& Loewy (1979). The CDP- $\left[{ }^{14} \mathrm{C}\right]$ gro formed from $\mathrm{L}-\left[\alpha_{-}{ }^{14} \mathrm{C}\right] \mathrm{glycerol}$ phosphate was determined in the nucleotide-containing fraction eluted from active charcoal. For reasons of economy, the $\mathrm{L}-\left[\alpha^{-14} \mathrm{C}\right] \mathrm{gro} \mathrm{P}$ was used at a less than saturating concentration, approximately one-fourth of the apparent $K_{\mathrm{m}}$ of $6.2 \times 10^{-4} \mathrm{M}$ (Glaser, 1965). Under the assay conditions used, the measured rate of accumulation of CDP- $\left[{ }^{14} \mathrm{C}\right]$ gro was proportional to the quantity of protein present in the crude cytosol fraction of the wildtype up to at least $500 \mu \mathrm{g}$. In most cases 10 -fold lower amounts of enzyme were assayed. To obtain measurable amounts of CDP-gro formation with enzyme deficient strains, 10- to 20-fold higher concentrations of extract or of substrates, or of both simultaneously, were employed. Initially, following Glaser \& Loewy (1979), the reaction mixture contained $10 \mu \mathrm{mol}$ Tris $/ \mathrm{HCl}\left(\mathrm{pH} 7 \cdot 5\right.$ ), $2 \mu \mathrm{mol} \mathrm{MgCl}_{2}$,
$0.2 \mu \mathrm{mol}$ EDTA, $0.25 \mu \mathrm{mol}$ CTP and $0.1 \mu \mathrm{mol} \mathrm{L}-\left[\alpha^{-14} \mathrm{C}\right]$ glycerol 3phosphate $\left(1 \mu \mathrm{Ci} \mathrm{mmol}^{-1}\right)$ in a final volume of $700 \mu$ l. After finding that $1 \%(\mathrm{w} / \mathrm{v})$ bovine serum albumin (BSA) efficiently stabilized the gro-PCT activity at temperatures above $30^{\circ} \mathrm{C}$ (see Results), it was routinely added to the reaction mixture during assay at all temperatures employed.

The enzyme-containing cytosol, after being thawed on ice, was prewarmed to the assay temperature just prior to addition to all remaining components of the reaction mixture. After $10 \mathrm{~min}$ incubation, in the majority of cases, the reaction was stopped by addition of $700 \mu \mathrm{l}$ trichloroacetic acid $(2 \%, \mathrm{w} / \mathrm{v})$ in acetate buffer $(\mathrm{pH} 4 \cdot 2 ; 0 \cdot 15 \mathrm{M})$. After 30 min on ice, precipitated proteins were removed by centrifugation. The supernatant contains the CDP- $\left[{ }^{4} \mathrm{C}\right]$ glycerol formed, which was separated from $\left[\alpha^{-1+} \mathrm{C}\right]$ groP by adsorption to, and elution from, active charcoal as described above (method ii). In the course of the experiments described below, the specific activity of gro-PCT in extracts of the wild type strain, measured under standard conditions, fell from around 30 units, initially, to a stable figure of 7 units. One unit is defined as the activity yielding $1 \mathrm{nmol}$ CDP-glycerol $\mathrm{min}^{-1}$ (mg protein in the extract) $)^{-1}$. Several control experiments were performed, varying the method of extract preparation. The results did not allow identification of the factor(s) responsible for the decrease in activity. Nevertheless, comparison with previous results revealed that the

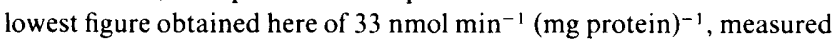
in the presence of 10 -fold higher concentrations of $\alpha$-groP and CTP than those in the standard assay, is close to that reported (Anderson et al., 1973) for a partially purified preparation of gro-PCT. When assayed under the standard (non-saturating) conditions employed here, the final figure of 7 units is about one-half the value (between 14 and 19 units) reported by Glaser \& Loewy (1979) for a partially purified enzyme preparation.

Apparent molecular size determination of gro-PCT. Exclusion from a molecular sieve was employed. A $200 \mu \mathrm{l}$ aliquot, containing $470 \mu \mathrm{g}$ cytosol protein of the strain carrying the $\operatorname{tag}^{+}$allele, was introduced onto a column $(1.0 \times 30 \mathrm{~cm}, 23.5 \mathrm{ml})$ of Superose 12 equilibrated with the same buffer (TEM, see above) as used for elution. Fractions $(500 \mu \mathrm{l})$ collected were assayed for gro-PCT and activity was found in a single peak spread over four fractions with an apparent molecular mass of about $30.5 \mathrm{kDa}$ based on the exclusion volumes of molecular size standards, BSA (67 kDa), ovalbumin ( $43 \mathrm{kDa})$, chymotrypsinogen A $(25 \mathrm{kDa})$ and ribonuclease $\mathrm{A}(13.7 \mathrm{kDa})$.

\section{Results}

Incorporation of $\left[2-{ }^{3} \mathrm{H}\right] \mathrm{glycerol}$ into the soluble pool and macromolecular fractions of $B$. subtilis 168 strains bearing mutations in different tag genes

Eleven $B$. subtilis 168 thermosensitive mutants bearing linked mutations in at least two different tag genes (Briehl et al., 1989; Honeyman \& Stewart, 1989; Mauël et al., 1989), were examined, under restrictive conditions, for incorporation of $\left[2-{ }^{3} \mathrm{H}\right] \mathrm{glycerol}$ into macromolecular fractions and accumulation of CDP-glycerol, a specific precursor of poly(groP). To attenuate the effects of heat shock, exponentially growing cultures were brought up to the restrictive temperature, $47^{\circ} \mathrm{C}$, over a $12-14 \mathrm{~min}$ transition period. Immediately upon reaching $47^{\circ} \mathrm{C}$, cultures were diluted and pulse-labelled with $\left[2-{ }^{3} \mathrm{H}\right] \mathrm{gly}-$ cerol. Aliquots were filtered and the cells, after washing, 
Table 2. Incorporation of $\left[2-{ }^{3} \mathrm{H}\right] \mathrm{glycerol}$ into the insoluble fraction and accumulation of

$C D P-\left[2-{ }^{3} \mathrm{H}\right] \mathrm{glycerol}$ in the soluble fraction of Bacillus subtilis 168 isogenic mutant strains bearing tag or lss markers during a 5 min pulse at $47^{\circ} \mathrm{C}$, the non-permissive temperature

\begin{tabular}{|c|c|c|c|c|c|c|c|c|}
\hline \multirow[b]{2}{*}{ Strain* } & \multicolumn{2}{|c|}{$\begin{array}{l}\text { Macromolecular } \\
\text { (insoluble) fraction }\end{array}$} & \multicolumn{6}{|c|}{$\begin{array}{l}\text { Soluble fraction glycerol equivalents } \\
\left.[\text { nmol (mg cell dry wt })^{-1}\right]\end{array}$} \\
\hline & $\begin{array}{c}\text { Glycerol† } \\
\text { [nmol (mg } \\
\text { cell dry wt })^{-1} \text { ] }\end{array}$ & $(R) \ddagger$ & $\begin{array}{l}\text { Total } 100^{\circ} \mathrm{C} \\
\text { water extract }\end{array}$ & $(R) \ddagger$ & $\begin{array}{c}\text { Non- } \\
\text { nucleotide }\end{array}$ & $(R) \ddagger$ & $\begin{array}{c}\text { CDP-gro§ } \\
\text { [nmol (mg } \\
\text { cell dry wt })^{-1} \text { ] }\end{array}$ & $(R) \ddagger$ \\
\hline L6653 $\operatorname{tag} B I$ & 42 & $(0 \cdot 21)$ & 14 & $(4 \cdot 0)$ & $3 \cdot 3$ & $(1.9)$ & 10 & (12) \\
\hline L665I tagD 11 & 37 & $(0 \cdot 18)$ & 2 & $(0 \cdot 6)$ & $1 \cdot 4$ & $(0 \cdot 8)$ & $0 \cdot 13$ & $(0 \cdot 16)$ \\
\hline $\mathrm{L} 6654 \operatorname{tag} F 1$ & 94 & $(0 \cdot 47)$ & 8 & $(2 \cdot 3)$ & $2 \cdot 5$ & $(1 \cdot 5)$ & $4 \cdot 6$ & $(5 \cdot 8)$ \\
\hline L2129lssA29\| & 78 & $(0 \cdot 39)$ & 9 & $(2 \cdot 6)$ & 1.9 & $(1 \cdot 1)$ & $3 \cdot 8$ & $(4 \cdot 8)$ \\
\hline L2123 lssB23\| & 84 & $(0 \cdot 42)$ & 12 & $(3 \cdot 1)$ & $4 \cdot 5$ & $(2 \cdot 6)$ & $3 \cdot 4$ & $(4 \cdot 3)$ \\
\hline 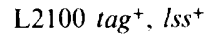 & 199 & (1) & $3 \cdot 5$ & (1) & $1 \cdot 7$ & (1) & $0 \cdot 8$ & (1) \\
\hline
\end{tabular}

* Relevant mutations only shown.

+ Calculated from the specific activity $\left(2 \mathrm{Ci} \mathrm{mol}^{-1}\right)$ of $\left[2-{ }^{3} \mathrm{H}\right] \mathrm{glycerol}$ in the medium. It is assumed that all cellular glycerol is obtained from exogenous glycerol without dilution. If, as appears unlikely, endogenous synthesis were to occur, there is no reason to expect differences between a set of isogenic strains (see Table 1).

$\ddagger(R)$ represents the ratio of incorporation into the mutant compared with that into the wild-type strain.

$\S$ Radioactivity adsorbed to charcoal is essentially accounted for by CDP-glycerol (Methods and Results).

\| Markers involved in the synthesis of peptidoglycan (Brandt \& Karamata, 1987).

and resuspension in water, were placed in a boiling water bath. The distribution of label between the filtrate, containing the soluble precursors, and the insoluble fraction was determined. Comparison of strains bearing representative mutations (Table 2 ) revealed that, relative to the $\operatorname{tag}^{+}$allele, $\operatorname{tag} F I$ and $\operatorname{tag} B I$ (formerly $\operatorname{tag}-I$ ) mutations conferred a three- to fourfold increase in the $\left[2-{ }^{3} \mathrm{H}\right]$ glycerol in the soluble fraction, which points to a substantial increase in the CDP-glycerol pool, following transfer to restrictive conditions, where synthesis of wall teichoic acid is inhibited (Briehl et al., 1989). The remaining mutation, tagDll (tag- 11$)$, was associated with a soluble pool virtually indistinguishable from that of the wild type, even though showing an inhibition of teichoic acid synthesis comparable to that of the other tag mutations. The phenotype of tag DII-bearing strains, clearly distinct from that conferred by $\operatorname{tag} B l$, is consistent with the genetic evidence that the relevant mutations map in different genes (Mauël et al., 1991).

To assess if the increase in $\left[{ }^{3} \mathrm{H}\right]$ glycerol-containing pools is specific to $\operatorname{tag} B$ and $\operatorname{tag} F$ markers, incorporation of $\left[2-{ }^{3} \mathrm{H}\right] \mathrm{glycerol}$ into four thermosensitive mutants bearing different lss markers (Brandt \& Karamata, 1987) was examined. The latter strains were shown to be affected in different steps of the synthesis of soluble precursors of peptidoglycan (PG) (Brandt \& Karamata, 1987; Roten et al., 1991). It appeared (Table 2, and data not presented) that all the lss loci were characterized by significantly increased soluble pools and a reduced incorporation of $\left[2-{ }^{3} \mathrm{H}\right] \mathrm{glycerol}$ into the macromolecular fraction which were comparable to those associated with $\operatorname{tag} F$ markers (see below). This result is consistent with a reduction of glycerol incorporation into poly(groP), which is probably the consequence of a prior inhibition of PG synthesis. Indeed, synthesis of both polymers occurs coordinately in B. subtilis, and teichoic acid chains are attached to those of PG made simultaneously (Mauck \& Glaser, 1972).

The rate of incorporation of label into the insoluble fraction revealed some striking differences between tagbearing mutants (Table 2). While significant reductions, relative to the wild-type, were associated with all three markers, that for $\operatorname{tagFl}$ was $50 \%$, whereas those for the remaining markers were more pronounced, i.e. nearly $75 \%$ for $\operatorname{tag} B 1$ and $80 \%$ for $\operatorname{tag} D 11 .\left[2-{ }^{3} \mathrm{H}\right]$ Glycerol labels essentially three fractions in B. subtilis 168 (Sargent, 1973 ; H. M. Pooley, unpublished results); $75 \%$ is accounted for by poly(groP), and the remainder is distributed, in roughly equivalent amounts, in lipid and lipoteichoic acid. Thus, the reduction in glycerol incorporation associated with all tag mutations examined is consistent with the markedly reduced phosphate contents of isolated cell walls (Briehl et al., 1989) and suggests a selective slowing of wall teichoic acid synthesis. Eight more strains (Briehl et al., 1989), each carrying a different mutation in the $\operatorname{tag} F$ locus, behaved similarly to that bearing $\operatorname{tag} F 1$ (data not presented). However, mutations $\operatorname{tag} F 14, F 16, F 18$ or $F 19$, associated with a leaky phenotype (Briehl et al., 1989), were characterized by a less pronounced decrease in macromolecular synthesis, as well as by smaller increases in the soluble pool. 


\section{Analysis of CDP-glycerol and non-nucleotide glycerol- containing pools in tag mutants}

To separate nucleotides from other soluble precursors, extracts obtained in boiling water (see above) were treated with activated charcoal. Nucleotide precursors were processed by paper chromatography for identification of CDP-glycerol and quantification of radioactivity in isolated spots (see Methods). It appeared that CDPglycerol represents about $30 \%$ of the total soluble label for the wild-type. For strains carrying $\operatorname{tag} B$ or $\operatorname{tag} F$ mutations, the amount of CDP-glycerol was 6- to 12-fold higher than in the wild-type. Following expression of the phenotype associated with $\operatorname{tag} F$ and $\operatorname{tag} B$ mutations, the measured amounts of CDP-glycerol were between 4.6 and $10 \mathrm{nmol}(\mathrm{mg} \text { cell dry weight })^{-1}$, as against 0.8 for the tag $^{+}$allele. These figures are comparable to those reported (Shaw et al., 1970) for the major soluble precursor, CDP-ribitol, in teichoic acid deficient mutants of Staphylococcus aureus and their parent strain: 3 and $0.4 \mathrm{nmol}$ ( $\mathrm{mg}$ cell dry weight $)^{-1}$, respectively. Increased pools of CDP-glycerol were found in all strains (Briehl et al., 1989) carrying $\operatorname{tag} F$ markers (data not presented). This accumulation of a specific poly(groP) teichoic acid precursor, CDP-glycerol, is consistent with a block in wall teichoic acid synthesis. $\operatorname{tag} D / 1$ contrasts strikingly with other tag mutations, since it confers a considerably reduced CDP-glycerol pool, barely $16 \%$ of that of the $\mathrm{tag}^{+}$-bearing strain. This failure to accumulate CDP-glycerol under restrictive conditions, where its incorporation into the wall is strongly inhibited (Briehl et al., 1989) argues in favour of a block in CDP-glycerol formation. The function affected by $\operatorname{tag} D / 1$ is not primarily concerned with glycerol uptake or glycerol kinase activity since, under restrictive conditions, glycerol incorporation into the macromolecular fraction continues with linear kinetics, albeit at a reduced rate, for a generation at least (data not presented).

Interestingly, label in the non-nucleotide fraction of the soluble pool (Table 2), of which $\alpha-\left[2-{ }^{3} \mathrm{H}\right] \mathrm{groP}$, the immediate precursor of CDP-glycerol, forms about half (not presented), was also apparently somewhat increased in strains bearing $\operatorname{tag} B I$ and $\operatorname{tag} F$ markers (Table 2). The tagD 11 mutation was again exceptional in not being associated with any apparent accumulation of $\alpha$-groP (see Discussion).

\section{gro-PCT activity in crude cytosol fractions of strains} bearing tag mutations

The enzyme gro-PCT, responsible for synthesis of CDPglycerol from $\alpha$-groP and CTP, appeared to be the prime candidate for the deficient activity in strain L6601 (tagD11). The enzyme activity was assayed at $25^{\circ} \mathrm{C}$ on
Table 3. gro-PCT activity in the crude cytosol fraction of $B$. subtilis 168 strains bearing mutations in different tag genes: thermosensitivity of gro-PCT activity in a tagD-bearing mutant

\begin{tabular}{|c|c|c|c|}
\hline \multirow[b]{2}{*}{ Strain* } & \multicolumn{3}{|c|}{ gro-PCT $\dagger\left[\mathrm{nmol} \min ^{-1}(\mu \mathrm{g} \text { protein })^{-1}\right]$} \\
\hline & $25^{\circ} \mathrm{C}$ & $42^{\circ} \mathrm{C}$ & $R_{42 / 25}$ \\
\hline L5087 tag $^{+}$ & $6 \cdot 4 \pm 0 \cdot 2$ & $5 \cdot 2 \pm 0 \cdot 2$ & 0.8 \\
\hline $\begin{array}{l}\text { L6456 } \operatorname{tag} F 1 \\
\text { L6604 } \operatorname{tag} F 14 \\
\text { L6605 } \operatorname{tag} F 15\end{array}$ & $\begin{array}{l}2 \cdot 5 \pm 0 \cdot 1 \\
5 \cdot 6 \pm 0 \cdot 2 \\
3 \cdot 4 \pm 0 \cdot 3\end{array}$ & $\begin{array}{l}2 \cdot 3 \pm 0 \cdot 2 \\
5 \cdot 1 \pm 0 \cdot 1 \\
3 \cdot 1 \pm 0 \cdot 1\end{array}$ & $\begin{array}{l}0.9 \\
0.9 \\
0.9\end{array}$ \\
\hline L6476 $\operatorname{tag} B 1$ & $3 \cdot 8 \pm 0 \cdot 1$ & $2 \cdot 6 \pm 0 \cdot 2$ & $0 \cdot 7$ \\
\hline L6601 tagDII & $0.08 \pm 0.02$ & $<0.01$ & $<0 \cdot 1$ \\
\hline
\end{tabular}

- Relevant mutations only shown.

$\dagger$ Specific activity was measured under standard conditions (see Methods) at the temperature indicated, with $50 \mu \mathrm{g}$ protein per assay, except for tagD11, where $1 \mathrm{mg}$ of extract protein was used. Results shown are mean values, with standard deviations, of a minimum of two separate assays; for $\operatorname{tagD11}$ and $\operatorname{tag}^{+}$alleles, four separate cytosol preparations were assayed.

$\ddagger$ The ratio of activity measured at $42^{\circ} \mathrm{C}$ compared with that at $25^{\circ} \mathrm{C}$

crude extracts obtained from cultures grown at $30{ }^{\circ} \mathrm{C}$ (Table 3 ). While gro-PCT activity was readily detectable in extracts of the wild-type, as well as in those of mutants L6604 ( $\operatorname{tag} F 14)$ and L6605 ( $\operatorname{tag} F 15)$, it was practically undetectable in that of mutant L6601 (tagD11). This result, in agreement with the observed large increases in the CDP-glycerol pool associated with mutations $\operatorname{tag} F 1$ and $\operatorname{tag} B 1$, implies that gro-PCT is not affected by mutations in the $\operatorname{tag} F$ and $\operatorname{tag} B$ genes. Assay of 20 -fold higher amounts of crude extracts from strain L6601 (tagD11) did yield a detectable activity. However, the specific activity thus measured was 100 -fold lower than that of the wild-type strain: 0.08 versus $6.4 \mathrm{nmol} \mathrm{min}^{-1}$ (mg protein $)^{-1}$. Assay of amounts as high as $1 \mathrm{mg}$ cytosol protein in the presence of 10 -fold higher concentrations of both substrates, CTP and $\alpha$-groP, yielded specific activities about five times higher: 0.43 and $33 \mathrm{nmol}$ $\mathrm{min}^{-1} \mathrm{mg}^{-1}$ for strains L6601 (tag D 11) and L5087, (wildtype), respectively. The strongly reduced gro-PCT activity measured in cell-free extracts of mutant L660l at $25^{\circ} \mathrm{C}$, below the permissive growth temperature, is entirely consistent with the failure to accumulate a pool of CDP-gro at the non-permissive temperature. The alternative possibility of an inhibitor of this enzyme being present in the extracts of this mutant was examined by measuring the gro-PCT activity when extracts from mutant L6601 (tagD11) and the $\mathrm{tag}^{+}$strain were pooled in equal proportions. Gro-PCT activity was found to be strictly proportional to the amount of $\mathrm{tag}^{+}$ cytosol protein, arguing in favour of a defective protein 
and against the presence of an inhibitor in the mutant extract.

\section{Thermostability of the gro-PCT in extracts of strains bearing mutations in $\operatorname{tag} A, \operatorname{tag} B$ and $\operatorname{tag} F$ genes}

Assaying gro-PCT in extracts of the wild-type strain at different temperatures showed that temperatures above $30{ }^{\circ} \mathrm{C}$ strongly diminished the measured activity: at $37^{\circ} \mathrm{C}$, it was barely $30 \%$ of that at $30^{\circ} \mathrm{C}$, whereas at $42{ }^{\circ} \mathrm{C}$, no activity could be detected. Stabilization of the activity of the wild-type enzyme at higher temperatures was attempted by addition of bovine serum albumin (BSA). In the presence of $1 \%(\mathrm{w} / \mathrm{v}) \mathrm{BSA}$ the measured activity at $37^{\circ} \mathrm{C}$ was identical to that at $30^{\circ} \mathrm{C}$, whereas at $42{ }^{\circ} \mathrm{C}$, it was barely $20 \%$ lower. The growth temperature of the culture from which the extracts were prepared did not influence this result (not shown). Comparison of the gro-PCT activities (Table 3 ) at two assay temperatures ( 42 and $25^{\circ} \mathrm{C}$ ) expressed as the ratio $R_{42 / 25}$ did not reveal significant differences with respect to the wild-type $\left(R_{42 / 25}=0.84\right)$ for extracts of three representative strains carrying $\operatorname{tag} F$ markers $-\operatorname{tag} F 1, F 14$ and $F 15$. With an $R_{42 / 25}$ of $0 \cdot 7, \operatorname{tagBl}$ may be associated with a slightly more pronounced temperature sensitivity. This absence of thermosensitivity was only to be expected in view of the rapid accumulation of CDP-glycerol in these strains following transfer to the non-permissive temperature. A striking contrast was offered by the tagDII-bearing mutant. At the non-permissive temperature, gro-PCT activities were dramatically reduced $\left(R_{42 / 25} \leq 0 \cdot 1\right)$, implying the existence of a modified, heat-sensitive protein, strongly suggesting that the mutation affects the structural gene of the gro-PCT.

\section{Apparent molecular size determination}

Passage through a Superose 12 column of the crude cytosol of the wild-type strain L5087 yielded gro-PCT activity in a single peak with an apparent molecular size of about $30.5 \mathrm{kDa}$. Comparison with the mass, $14.5 \mathrm{kDa}$, of the putative polypeptide predicted from the nucleotide sequence of the $\operatorname{tag} D$ gene (Mauël et al., 1991) suggests the presence of a dimer.

\section{Discussion}

The results presented here reveal that $\operatorname{tag} D$ is most likely to be the structural gene of gro-PCT, an enzyme specific for the synthesis of poly(groP), the major cell wall anionic polymer in B. subtilis 168 . Thus, they eliminate any remaining doubts (Rogers et al., 1974; Rogers \& Taylor, 1978) that the conditional lethal phenotype of a $\operatorname{tag} D$-bearing mutant may not be a consequence of a single primary defect specific to teichoic acid synthesis. The likelihood that other tag genes encode poly(groP)specific proteins is also reinforced. The conclusion that poly(groP) synthesis is essential for growth (Karamata $e t$ al., 1987; Briehl et al., 1989; Mauël et al., 1989) is now made explicit.

It is interesting that the existence of another $B$. subtilis mutant deficient in gro-PCT has been reported (Rosenberger, 1976; Rogers, 1979). Although, like the tagDbearing mutant, it grew as a coccus and was deficient in wall phosphate, this mutant was reported not to have a conditional lethal phenotype. However, in the absence of any published data, it is difficult to evaluate this observation. Furthermore the mutant is likely to be genetically complex. In this respect it may resemble the partial revertants of other tag-bearing mutants (Shifflett et al., 1977) which, at the restrictive temperature, grow slowly, form small colonies, and have low but significant amounts of phosphate in their walls.

In comparison with all other strains, where ${ }^{3} \mathrm{H}$ labelled $\alpha$-groP forms about $50 \%$ of the label in the nonnucleotide pool, the low level of ${ }^{3} \mathrm{H}$ label in the soluble pool of the gro-PCT-deficient mutant implies a failure to accumulate $\alpha$-groP. Formation of the latter compound is not blocked in the $\operatorname{tag} D 11$-bearing mutant, however, since incorporation of $\left[{ }^{3} \mathrm{H}\right]$ glycerol into some macromolecular fractions continues. Furthermore, the gene encoding glycerol kinase maps at $75^{\circ}$, together with other genes involved in glycerol metabolism (Lindgren \& Rutberg, 1974). The absence of accumulation of $\alpha$-groP presumably means, therefore, that glycerol uptake is subject to feedback inhibition by a relatively small increase in the $\alpha$-groP pool. In the case of all other tag markers, presence of larger amounts of ${ }^{3} \mathrm{H}$ in the nonnucleotide pool is probably due to back formation of $\alpha$ groP from the accumulated CDP-glycerol by an active CDP-glycerol pyrophosphatase, known to be present in this organism (Glaser, 1965).

Pulse-labelling experiments with $\left[2{ }^{3} \mathrm{H}\right] \mathrm{glycerol}$, immediately after transfer to $47^{\circ} \mathrm{C}$, suggest that the very low cell wall teichoic acid content of all tag-bearing mutants (Briehl et al., 1989), observed two or more hours after transfer to $47^{\circ} \mathrm{C}$, is a consequence of a rather rapid expression of the relevant tag mutations. However, the increased pool of CDP-glycerol which in all but one instance accompanies this phenotype is shown here not to be limited to mutations almost certainly affecting enzymes of poly(groP) synthesis. Indeed, accumulation of this precursor is also conferred by mutations affecting different steps of the synthesis of soluble peptidoglycan precursors. This result is not surprising, since transfer of any membrane-linked poly(groP) to nascent peptidoglycan is coupled to the synthesis of the latter (Mauck \& 
Glaser, 1972). However, in the case of tag mutations, a block in teichoic acid synthesis does not appear to prevent synthesis of peptidoglycan (Rogers et al., 1974; Briehl et al., 1989; H. M. Pooley, unpublished observations).

The isolation of clones containing tag genes (Honeyman \& Stewart, 1988; Mauël et al. , 1989) and subsequent nucleotide sequencing (Honeyman \& Stewart, 1989; Mauël, et al., 1991) have revealed the presence of six genes grouped in two operons, one containing $\operatorname{tag} A, B$ (formerly $\operatorname{tag} A$ ), and $C$, and the other containing $\operatorname{tag} D, E$ $(g \operatorname{ta} A)$ and $F(\operatorname{rod} C)$ genes. So far, products of only two genes have been probably identified, namely, the UDPglucose poly(groP)- $\alpha$-glucosyltransferase likely to be encoded by $\operatorname{tag} E$ (Young, 1967; Young et al., 1969; Brooks et al., 1971) and gro-PCT encoded by $\operatorname{tag} D$. Since two out of the three genes of the $\operatorname{tag} D E F$ operon encode enzymes specifically involved in the synthesis of the glucosylated poly(groP), it is most likely that the remaining gene also encodes a protein concerned with the synthesis of this polymer.

This conclusion raises the question of the striking absence from the mutant collection obtained by the rationale of Briehl et al. (1989) of mutations affecting the $\operatorname{tag} A B C$ operon. All of the latter mutants harbour mutations in genes $\operatorname{tag} F$ or $\operatorname{tag} D$. Indeed, up to eight mutations in this collection map in a single gene, $\operatorname{tag} F$ (Briehl et al., 1989), and one in the small gene tagD (Mauël, et al., 1991) belonging to the same operon, $\operatorname{tag} D E F$. Based on size calculated from nucleotide sequences (Honeyman \& Stewart, 1989; Mauël et al., 1991), the frequency of mutations obtained (approximately one per $8 \mathrm{kDa}$ of protein) is apparently not very different for these two target genes. Many mutations in the remaining locus in this operon, $\operatorname{tag} E(\mathrm{gta} A)$ have been identified (Young, 1967; Pooley et al., 1987). However, they do not have a conditional lethal phenotype characteristic of mutations in the remaining genes of this operon: non-glucosylated poly(groP) is incorporated into the cell wall of tagE-containing mutants (Young, 1967). Interestingly, unlike most, if not all, $\operatorname{tag} F$ mutations in our collection, as well as $\operatorname{tag} F 1$ ( $\operatorname{rod} C l)$, obtained independently (Briehl et al., 1989), the only mutation to have been mapped in the $\operatorname{tag} A B C$ operon, $\operatorname{tag} B 1$, remains sensitive to $\phi 29$ at $37^{\circ} \mathrm{C}$ and higher temperatures (H. M. Pooley, unpublished observations). If this property were to be shared by other mutations in this operon, their elimination during the enrichment procedure (Briehl et al., 1989) could account for their absence from the above-mentioned collection. Introducing new mutations by in vitro mutagenesis of the relevant clones should allow this question to be answered.

Interest in components regulating bacterial morphogenesis led to the isolation, some 20 years ago (Satta et al.,
1969; Boylan \& Mendelson, 1969; Rogers et al., 1970) of conditional lethal mutants affected in cell shape, in several rod-shaped organisms. Our results imply the identification in one organism, at least, of one such component. Nevertheless, the identification of an essential function, and the knowledge of some of the complex abnormalities in the physiology, surface growth and morphology of the cell that follow a block in this function, in no way furnish a ready-made understanding of the role(s) of poly(groP) during normal growth and division. This challenge remains to be met.

\section{References}

Anderson, R. G., Douglas, L. J., Hussey, H. \& Baddiley, J. (1973). The control of bacterial cell walls. Interaction in the synthesis of nucleotide precursors. Biochemical Journal 136, 871-876.

BANDURSKY, R. S. \& AXELROD, B. (1952). The chromatographic identification of some biologically important phosphate esters. Journal of Biological Chemistry 193, 405-410.

Boylan, R. J. \& Mendelson, N. H. (1969). Initial characterization of a temperature-sensitive rod-mutant of Bacillus subtilis. Journal of Bacteriology 100, 1316-1321.

Boylan, R. J., Mendelson, N. H., Brooks, D. \& Young, F. E. (1972). Regulation of the bacterial cell wall: analysis of a mutant of Bacillus subtilis defective in biosynthesis of teichoic acids. Journal of Bacteriology 110, 281-290.

BRADFORD, M. M. (1976). A rapid and sensitive method for the quantitation of microgram quantities of protein utilizing the principle of protein-dye binding. Analytical Biochemistry 72, 248254.

BrandT, C. \& Karamata, D. (1987). Thermosensitive Bacillus subtilis mutants which lyse at the non-permissive temperature. Journal of General Microbiology 133, 1159-1170.

Briehl, M., Pooley, H. M. \& Karamata, D. (1989). Mutants of Bacillus subtilis 168 thermosensitive for growth and wall teichoic acid synthesis. Journal of General Microbiology 135, 1325-1334.

Brooks, D., MaYs, L. L., Hatefi, Y. \& Young, F. E. (1971). Glucosylation of teichoic acid: solubilization and partial characterization of the uridine diphosphoglucose:polyglycerolteichoic acid glucosyl transferase from membranes of Bacillus subtilis. Journal of Bacteriology 107, 223-229.

DANIELS, M. J. (1969). Lipid synthesis in relation to the cell cycle of Bacillus megaterium KM and Escherichia coli. Biochemical Journal 115, 697-701.

Glaser, L. (1965). The synthesis of teichoic acids. IV. On the regulation of cytidine 5'-diphosphateglycerol concentration. Biochimica et Biophysica Acta 101, 6-15.

Glaser, L. \& Loewy, A. (1979). Control of teichoic acid synthesis during phosphate limitation. Journal of Bacteriology 137, 327-331.

Honeyman, A. L. \& Stewart, G. C. (1988). Identification of the protein encoded by rodC, a cell division gene from Bacillus subtilis. Molecular Microbiology 2, 735-741.

Honeyman, A. L. \& Stewart, G. C. (1989). The nucleotide sequence of the rodC operon of Bacillus subtilis. Molecular Microbiology 3, 1257-1268.

Karamata, D. \& Gross, J. D. (1970). Isolation and genetic analysis of temperature-sensitive mutants of Bacillus subtilis defective in DNA synthesis. Molecular and General Genetics 108, 277-287.

Karamata, D., McConnell, M. \& Rogers, H. J. (1972). Mapping of rod mutants of Bacillus subtilis. Journal of Bacteriology 111, 73-79.

Karamata, D., Pooley, H. M. \& Monod, M. (1987). Expression of heterologous genes for wall teichoic acid in Bacillus subtilis 168. Molecular and General Genetics 207, 73-81. 
Lindgren, V. \& Rutberg, L. (1974). Glycerol metabolism in Bacillus subtilis : gene enzyme relationships. Journal of Bacteriology 119, 431442.

MaUCK, J. \& Glaser, L. (1972). On the mode of in vivo assembly of the cell wall of Bacillus subtilis. Journal of Biological Chemistry 247, 1180 1187.

Mauël, C., Young, M., Margot, Ph. \& Karamata, D. (1989). The essential nature of teichoic acids in Bacillus subtilis as revealed by insertional mutagenesis. Molecular and General Genetics 215, 388 394.

Mauël, C., Young, M. \& Karamata, D. (1991). Genes concerned with synthesis of poly(glycerol phosphate), the essential teichoic acid in Bacillus subtilis strain 168, are organized in two divergent transcription units. Journal of General Microbiology 137, 929--941.

Paladini, A. C. \& Leloir, L. F. (1952). Studies on uridinediphosphate-glucose. Biochemical Journal 51, 426-430.

Pooley, H. M., Paschoud, D. \& Karamata, D. (1987). The gtaB marker in Bacillus subtilis 168 is associated with a deficiency in UDPglucose pyrophosphorylase. Journal of General Microbiology 133, $3481-3493$.

Rogers, H. J. (1979). Envelope growth and synthesis in rod mutants and protoplasts of bacilli. Advances in Microbial Physiology 19, 25-34.

Rogers, H. J. \& TAYLOR, C. (1978). Autolysins and shape change in rodA mutants of Bacillus subtilis. Journal of Bacteriology 135, 10321042.

Rogers, H. J., MCConnell, M. \& Burdett, I. D. J. (1970). The isolation and characterization of mutants of Bacillus subtilis and Bacillus licheniformis with disturbed morphology and cell division. Journal of General Microbiology 61, 155-171

Rogers, H. J., MCConnell, M. \& Hughes, R. C. (1971). The chemistry of the cell walls of rod mutants of Bacillus subtilis. Journal of General Microbiology 66, 297-308.

Rogers, H. J., Thurman, P. F., Taylor, C. \& Reeve, J. N. (1974) Mucopeptide synthesis by rod mutants of Bacillus subtilis. Journal of General Microbiology 85, 335-350.
Rosenberger, R. F. (1976). Control of teichoic and teichuronic acid biosynthesis in Bacillus subtilis 168 trp. Evidence for repression of enzyme synthesis and inhibition of enzyme activity. Biochimica et Biophysica Acta 428, 516-524.

Roten, C.-A. H., BrandT, C. \& Karamata, D. (1991). Genes involved in meso-diaminopimelate synthesis in Bacillus subtilis: identification of the gene encoding aspartokinase I. Journal of General Microbiology 137, 951-962.

SARGENT, M. G. (1973). Membrane synthesis in synchronous cultures of Bacillus subtilis 168. Journal of Bacteriology 116, 397-409.

Satta, G., Schito, G. C. \& Meloni, G. A. (1969). Transizione bastoncinosfera in un ceppo di Klebsiella pneumoniae. Ultrastruttura delle forme coccoidie tipiche ed anormi. Atti del $X V^{\circ}$ Congresso Nazionale di Microbiologia Torina-Saint Vincent 2, 247-253.

Shaw, D. R. D., Mirelman, D., Chatterjee, A. N. \& Park, J. T (1970). Ribitol teichoic acid synthesis in bacteriophage-resistant mutants of Staphylococcus aureus $\mathrm{H}^{*}$. Journal of Biological Chemistry 19, 5101-5106.

Shiflett, M. A., Brooks, D. \& Young, F. E. (1977). Cell wall and morphological changes induced by temperature shift in Bacillus subtilis cell wall mutants. Journal of Bacteriology 132, 681-690.

Strominger, J. L. (1962). Uridine and guanosine nucleotides of hen oviduct. Journal of Biological Chemistry 237, 1388-1392.

Young, F. E. (1967). Requirement of glucosylated teichoic acid for adsorption of phage in Bacillus subtilis 168. Proceedings of the National Academy of Sciences of the United States of America $\mathbf{5 8}$, 2377-2384

Young, F. E., Smith, C. \& Reilly, B. E. (1969). Chromosomal location of genes regulating resistance to bacteriophage in Bacillus subtilis. Journal of Bacteriology 98, 1087-1097

Young, M., Mauel, C., Margot, Ph. \& Karamata, D. (1989). Pseudo-allelic relationship between non-homologous genes concerned with biosynthesis of polyglycerol phosphate and polyribito phosphate teichoic acids in Bacillus subtilis strains 168 and W23. Molecular Microbiology 3, 1805-1812. 